\title{
Strategies and types of social and psychological adaptation of international students studying in London
}

\author{
Elena Yashchenko ${ }^{1}$, Ekaterina Shchelokova ${ }^{2}$, and Olga Lazorak ${ }^{2, *}$ \\ ${ }^{1}$ Emperor Alexander I St. Petersburg State Transport University (PGUPS), 190031, 9 Moskovsky pr., \\ St. Petersburg, Russia \\ ${ }^{2}$ South Ural State University (National Research University), 454080, 76 Lenin ave., Chelyabinsk, \\ Russia
}

\begin{abstract}
Results of the research on adaptation of foreign students of the technical and humanitarian directions of training studying in London in the number of 32 people are presented. The strategies of adaptive behaviour of foreign students are defined: positive (types of adaptability, interactivity), conformal (conformal and aloof types) and negative (depressive and nostalgic types of adaptation) - and interrelations of the revealed strategies with life sense, values and personal traits. The positive strategy, including adaptive and interactive types of adaptation, is characterized by 35 interrelations of these types of adaptation with personal and valuable-sense scales that demonstrates the comprehension of their life and orientation at self-actualization values. The nostalgic and depressive types defining the negative strategy of adaptation (37.5 per cent) don not promote socialization, self-actualization and effective social and psychological adaptation of foreign students. The nostalgic type of adaptation has 16 interrelations with research variables, and 13 of them are negative - with Personal traits, 1 positive - with Personal traits (neuroticism) and 2 negative - with Self-actualization and Values (prestige). It is defined that only the foreign students accepting the negative strategy of adaptation have an emotional unbalance and emotional discomfort.
\end{abstract}

\section{Introduction}

Modern conditions of formation of the united world post-industrial community and open information space are complicated by many social and psychological factors both intergroup (between the countries), and interpersonal interaction. Vital for the person becomes such quality as adaptability, i.e. the ability to adaptat in the conditions of the fluctuating (constantly changing) uncertainty. Many researches devote their attention to the questions of adaptation in its various aspects: W. Searle \& C. Ward [1], C. Ward \& A. Kennedy [2], J. W. Berry [3], A. V. Kravtsov [4], A. A. Nalchadzhyan [5], E. Yoon et al

\footnotetext{
* Corresponding author: lazolvas@ mail.ru
} 
[6], C. R. Glass \& C. M. Westmont [7], M.M. Doucerain et al [8], D. Güngör \& Perdu N. [9], Ng. T. Kin [10], etc.

Adaptation in its most general sense can be defined as the process of establishing the optimum compliance of the personality and the environment [5]. The most important type of adaptation in the light of current trends is the social and psychological adaptation, which represents the process of acquisition of a certain social and psychological status by people, mastering these or those social and psychological role functions [5].

The analysis of scientific sources has shown that there are two types of social and psychological adaptation: 1) progressive, providing realization of unity of interests, the purposes of the personality and groups of society; 2) regressive, shown as the formal adaptation which doesn't respond to the interests of society, development of this social group and the personality itself.

J. W. Berry [11] defines the four main strategies of adaptation: integration, assimilation, division and isolation. According to J. W. Berry, cross-cultural adaptation is the difficult phenomenon depending on a set of factors both external and internal including orientation of the personality [12], motivation, self-actualization [13], sphere of values of the personality [14], career orientation [15], etc.

The subject of the research is strategies and types of social and psychological adaptation of foreign university students, studying in new social and cultural conditions.

\section{Method}

Base of the research: the respondents were foreign and British students of the technical and humanitarian directions of training studying in London at universities of Goldsmiths, Queen Mary, Brunel and New York University in London. Number of respondents: 32 foreign students, the mean age was 21years old.

The object of the research is social and psychological adaptation of university students. The subject of the research is strategies, types and features of social and psychological adaptation of foreign university students. Research problems: 1) to define adaptive indicators of the foreign students; 2) to reveal personal and valuable-sense characteristics of types of social and psychological adaptation of foreign students in the course of professional socialization in the educational environment in London; 3) to define the main strategies of social and psychological adaptation of the foreign students trained in London. Research hypotheses: 1) social and psychological adaptation of students can be carried out in the form of one of three strategies: positive (types of adaptability, interactivity), negative (types of depressiveness, estrangement, nostalgia) и conformal (type of conformation); 2) scales of positive strategy of adaptation have more interrelations with valuable-sense characteristics (life values, purposes, motives and life senses) of foreign students studying in Great Britain than scales of negative and conformal strategy.

The collecting of empirical information was carried out by means of the following set of psycho-diagnostic techniques: "Adaptation of the personality to the new sociocultural environment" by L. V. Yankovsky; technique of diagnostics of social and psychological adaptation by K. Rogers and R. Dimond; "Adaptation to university" Crombag et al; "Scale of subjective wellbeing" in adaptation by M. V. Sokolova; "Test of life-sense orientations" (TLSO) by D. A. Leontiev; "Self-actualization test (short version)" by Jones, Crandall; "Reflexivity" by A. V. Karpov; "Career anchors" by E. Schein; "Axiological orientation of the personality" by A. V. Kaptsov; "Big Five” by O. P. John, L. P. Naumann \& C. J. Soto.

Results for interpretation have been received by means of statistical criteria t-Student, U-Mann-Whitney, H-Kruskal-Wallis, $\chi 2$-Pearson, correlation and dispersive analyses. The programs Excel 7.0, STATISTICA 8.0, SPSS 20.0, Corel Draw X4 have been used for processing of results of an empirical research and visualization of data. 


\section{Results and discussion}

The dominating types of adaptation of foreign students to new social and cultural conditions have been defined by us. The results are available in Table 1.

Table 1. Indicators of types of adaptation: the prevailing adaptation type of the foreign students studying in London $(\mathrm{N}=32)$.

\begin{tabular}{|l|c|c|c|c|}
\hline $\begin{array}{c}\text { Types } \\
\text { adaptation }\end{array}$ & $\begin{array}{c}\text { Mean } \\
\text { value } \\
(\mathrm{M})\end{array}$ & $\begin{array}{c}\text { Sigma } \\
(\sigma)\end{array}$ & $\begin{array}{c}\text { Number of } \\
\text { students with the } \\
\text { prevailing type, } \mathrm{n}\end{array}$ & $\begin{array}{c}\text { Number of } \\
\text { students with the } \\
\text { prevailing type, as } \\
\text { a percentage }\end{array}$ \\
\hline Adaptive & 9.22 & 3.00 & 17 & $53,13 \%$ \\
\hline Conformal & 7.14 & 1.94 & 2 & $6,25 \%$ \\
\hline Interactive & 8.86 & 2.40 & 9 & $28,13 \%$ \\
\hline Depressive & 6.11 & 2.70 & 6 & $18,75 \%$ \\
\hline Nostalgic & 7.36 & 2.66 & 6 & $18,75 \%$ \\
\hline Aloof & 6.50 & 1.96 & 1 & $3,13 \%$ \\
\hline
\end{tabular}

Note: 9 people have mixed adaptation type (their values are summarized in 2 lines that is why the sum is more than 32 people and 100 per cent).

The analysis of interrelations of types of social and psychological adaptation to the new social and cultural conditions with research scales - Personal traits, Life sense, Career orientation, Values, SPA, Academic adaptation, Well-being and Self-actualization - at foreign students has been carried out. The results are presented in the Figure 1.

The Figure 1 shows that we can unite 6 types of adaptation in pairs in 3 groups, and each of 2 types in each couple is as if the mirror, complementary copy of another: 1) adaptive and interactive (the interactive type is "poorer" on interrelations, than the adaptive one, but the general drawing of connections is similar) types making up the positive strategy of adaptation; 2) conformal and aloof (each of these types of adaptation has 1 positive connection with Career orientation and 1 negative with the scales of Life sense and Well-being) types, representing the conformal strategy; 3) the nostalgic and depressive types defining the negative strategy of adaptation. We note that in the structure of interrelations of the last couple of types negative interrelations with research scales are revealed.

The detailed analysis of the received results has shown that the strategies assumed in a hypothesis 1 are empirically picked out. Existence of the positive strategy including adaptive and interactive types of adaptation is completely confirmed, at the same time conformal and negative strategies are defined more precisely. The most part of foreign students $(81,26$ per cent; the third part of students have the mixed adaptation type) accept the positive strategy of adaptation which is characterized by multiple interrelations of adaptive and interactive types of adaptation with valuable-sense (22 interrelations at both types) and personal (12 interrelations) qualities.

The indicator of adaptive type is positively connected (has 19 interrelations) with scales of the valuable-sense block of our research.1 negative interrelation with Well-being ( $\mathrm{r}=-$ 0.485 ) is revealed that speaks about the condition of emotional wellbeing of the foreign students realizing the adaptive strategy of behaviour. The parameter of interactive type of adaptation at foreign students has 1 negative interrelation with an indicator of Reflexivity (perspective) $(\mathrm{r}=-0.355)$, and also 13 positive interrelations with personal and valuablesense scales. Foreign students with this type of adaptation to a larger extent are ready for the real, but not future activity and life. 

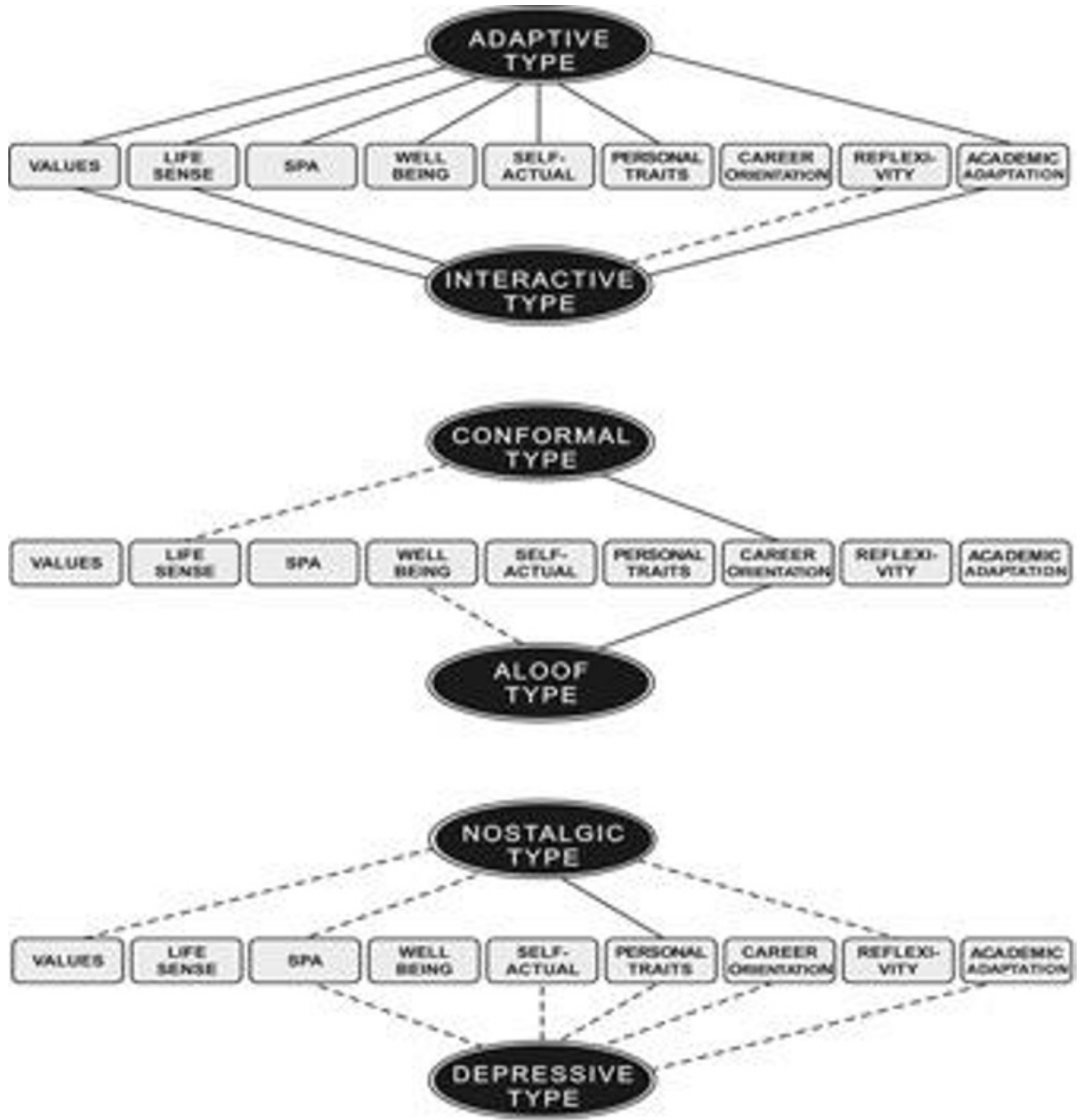

Fig. 1. Interrelations of types of adaptation to new sociocultural conditions with research scales at international students.

\section{Conclusion}

Personal and valuable-sense characteristics of types of social and psychological adaptation of foreign students in the course of professional socialization in the educational environment of London are revealed.

The main strategies of social and psychological adaptation of foreign students are defined: positive (types of adaptability, interactivity), conformal (conformal and aloof types) and negative (depressive and nostalgic types of adaptation). At least every third foreign student experiences difficulties in adaptation to new social and cultural and educational conditions of the host country.

The analysis of quantity and quality of interrelations of types of social and psychological adaptation with the research scales characterizing personal and valuablesense qualities has shown that the positive strategy of adaptation has the greatest number of interrelations. 


\section{References}

1. W. Searle, C. Ward, International Journal of Inrercultural Relations, 14, 449-464 (1990)

2. C. Ward, A. Kennedy, International Journal of Intercultural Relations, 18, 3 (1994)

3. J. W. Berry, International Journal of Intercultural Relations, 29 (2005)

4. A. V. Kravtsov, Social and psychological adaptation of foreign students to the higher school of Russia: Abstract of Cand. of Psych. Sciences (Moscow, 2008)

5. A.A. Nalchadzhyan, Psihologicheskaja adaptacija: mehanizmy $i$ strategii [Psychological adaptation: mechanisms and strategy] (Moscow, Eksmo, 2010)

6. E. Yoon, C. T. Chang, S. Kim, A. Clawson, S. E. Cleary, M. Hansen, A. Gomes, Journal of Counseling Psychology, 60 (2012)

7. C. R. Glass, C. M. Westmont, International Journal of Intercultural Relations, 38 (2014)

8. M. M. Doucerain, R. S. Varnaamkhaasti, N. Segalowitz, A. G. Ryder, Frontiers in Psychology, 6, 1111 (2015)

9. D. Güngör, N. Perdu, International Journal of Intercultural Relations, 56 (2017)

10. Ng. T. Kin, K. Wan Ching Wang, W. Chan, International Journal of Intercultural Relations, 59 (2017)

11. D. L. Sam, J. W. Berry (Eds.), The Cambridge Handbook of Acculturation Psychology (Cambridge University Press, Cambridge, 2006)

12. O. V. Lazorak, International Journal of Experimental Education, 2 (2014)

13. E. F. Yashchenko, Fundamental research - Series in Psychological Sciences, 10, 7 (2013)

14. A. V. Kaptsov, E. I. Kolesnikova, Samara Humanitarian Academy - Series in Psychology, 1, 17 (2015)

15. E. G. Shchelokova, Fundamental Research, 11, 4 (2013) 